\title{
Erratum: A Dynamic Tradeoff between Active and Passive Corruptions in Secure Multi-Party Computation
}

\author{
Martin Hirt ${ }^{1}$, Ueli Maurer ${ }^{1}$, and Christoph Lucas ${ }^{2}$ \\ ${ }^{1}$ ETH Zurich \\ \{hirt, maurer\}@inf.ethz.ch \\ ${ }^{2}$ ETH Zurich and Ergon Informatik AG \\ christoph. lucas@ergon.ch
}

R. Canetti and J.A. Garay (Eds.): CRYPTO 2013, Part II, LNCS 8043, pp. 203-219, 2013.

(C) International Association for Cryptologic Research 2013

\section{DOI 10.1007/978-3-642-40084-1_31}

The sequence of the authors should be in alphabetical order and therefore reads: "Martin Hirt, Christoph Lucas, Ueli Maurer" instead of "Martin Hirt, Ueli Maurer, Christoph Lucas". 